\title{
El espacio de las reducciones de la Provincia Jesuítica del Paraguay como construcción simbólica de la adaptación religiosa y socio-cultural
}

\section{Artículo científico}

Marcela Pezzuto ${ }^{1}$

UCA

Material original autorizado para su primera publicación en el Journal de Ciencias Sociales, Revista Académica de la Facultad de Ciencias Sociales de la Universidad de Palermo.

Recibido: 16-11-2015

Aceptado: 23-3-2016

Resumen: Nuestro objetivo es resignificar el espacio reduccional a través del estudio de su conformación y disposición físico-espacial. Realizaremos una lectura del espacio considerándolo como el resultado de la síntesis cultural y del liderazgo alcanzado por los religiosos y los indígenas, que revela un importante pensamiento simbólico sincrético.

En la disposición espacial de las poblaciones resulta notable el contraste entre "adentro" (espacio ordenado y seguro) y "afuera" (marcado por el peligro y el caos). La idea de delimitar ambos sitios estaba reforzada por signos que remitían a una reorganización de la realidad física viabilizada por el diseño urbanístico propio de una cultura razonante.

Estudiaremos los planos de las misiones como reproducciones intelectuales de una realidad modélica para luego centrarnos en el lenguaje simbólico que subyace en su construcción. Emplearemos los conceptos de utopía y heterotopía para, finalmente, realizar una lectura hermenéutica interpretativa de la composición que alcanzaron las urbes/reducciones.

Así, el resultado de nuestro estudio revela una representación octogonal. El número ocho como base

\footnotetext{
${ }^{1}$ Marcela Pezzuto es Doctora en Letras. Su ámbito de especialización han sido los estudios coloniales. Es profesora adjunta de la cátedra de Literatura Iberoamericana en la UCA. Posee publicaciones en revistas académicas nacionales e internacionales. En 2008 publicó en coautoría un libro dedicado a la literatura de viajes en el mundo iberoamericano. Correo electrónico: marcelapezzuto@gmail.com
} 
de ordenamiento cobra un relieve especial debido a la importante significación que ha tenido para el cristianismo. Desde esta perspectiva el plano de las misiones permite una lectura simbólica basada en la idea de que estos poblados constituían el lugar ideal para el desarrollo del hombre cristiano en sociedad. El poblado, entonces, constituía un emplazamiento religioso y cultural que procuraba que los indios alcanzaran una vida política, humana y de fe.

Palabras clave: Montoya, misión, organización, heterotopía

Abstract: The main goal here is to resignify the reductions' area through the study of their structure and their physico-spatial layout. A reading of the space will be done, considering it as the result of a cultural synthesis and of the leadership reached by priests and indigenous people, which reveals an important symbolic syncretic thought.

The contrast between the 'indoor' - a well-organized and safe area-and the 'outdoor' -marked by danger and chaos- is remarkable within the spatial layout of the settlements. The idea of delimiting both places was reinforced by signs that remitted to the reorganization of a tangible reality made viable by the urban design, typical of a rational culture.

The missions' plans will be studied as intellectual reproductions of a model reality, so as to focus, then, on the symbolic language which underlies in its construction. The concepts of Utopia and Heterotopia will be used lastly to carry out an interpretative hermeneutical reading of the compositon reached by the reductions.

In this way, the results of this paper reveal an octagonal representation. Number eight as an ordering basis becomes significant due to the crucial meaning it has had for Cristianity. From this point of view, the missions' map allows a symbolic reading based on the idea that these settlements established an ideal place for the development of Christian men within society. The settlement, then, constituted a religious and cultural area that sought to make the Indians reach a political, human and faithful life.

Keywords: Montoya, mission, organisation, hetherotopy

La finalidad de este artículo consiste en resignificar el espacio reduccional a través del estudio de su conformación y disposición físico-espacial. Pretendemos realizar una lectura del espacio considerado como el resultado de la síntesis cultural, religiosa y de liderazgo alcanzado entre religiosos e indígenas y que revela un importante pensamiento simbólico sincrético. Al respecto, la síntesis manifestada en la diagramación 
espacial dentro de las misiones representa un proceso gradual de adaptación que enfrentaron jesuitas y guaraníes.

Abordaremos el espacio de la reducción en su evolución desde el primer contacto -a partir de la aldea- hasta llegar a constituirse en un conglomerado de pueblos interconectados por vía fluvial y terrestre y con marcadas especializaciones productivas. En este recorrido observaremos las primeras configuraciones ideadas por los padres respecto de los asentamientos iniciales, cuánto se mantuvo la estructura de la originaria aldea indígena y qué aportes de la religión cristiana influyeron en la conformación del plano de las reducciones.

Nuestro estudio busca, de esta forma, abordar la evolución del concepto de Región hasta llegar al desarrollo del espacio de la Reducción. En definitiva, observaremos qué cambios ocurrieron desde la aldea hasta el pueblo misional.

\section{Anterior al contacto ${ }^{2}$}

Existen dos conceptos que resultan decisivos para abordar la interacción del hombre con su medio: uno es el espacio y el otro es la región. En primer lugar abordaremos el concepto de espacio indígena como el ámbito territorial que poseían las comunidades y, por lo tanto, el uso que hacían de las tierras heredadas por un patrimonio propio. La división de dicho espacio para la explotación de las riquezas se había producido naturalmente gracias a la presencia de aguas que marcaban la distribución y el uso de dichas tierras. Así, el agua se conformó en el gran ordenador del espacio de cada comunidad. Es decir, los ríos y los arroyos señalaron prontamente los límites de cada aldea.

La falta de herramientas para la labranza de la tierra junto con la aplicación del sistema de rozado hizo que los indígenas del grupo lingüístico tupí-guaraní fueran semi-sedentarios. La constatación del rápido agotamiento de los campos generó una importante conciencia sobre el uso de los recursos naturales en

\footnotetext{
2 En las siguientes líneas nos abocaremos al análisis de dos ideas: espacio y región. Para tal fin nos ha sido de gran utilidad y esclarecimiento el trabajo del Dr. Norberto Levinton El espacio jesuítico guaraní. La formación de una región cultural. Centro de Estudios antropológicos de la Universidad Católica (CEADUC). Biblioteca de Estudios Paraguayos- Volumen 80. Asunción, 2009. Ha sido de esta obra que hemos extraído el material teórico para la elaboración de los conceptos que se mencionan.
} 
general, de manera que se practicó la recolección, la caza y la pesca ${ }^{3}$ de forma no depredatoria. De esta forma los indígenas sólo utilizaban lo necesario, revelando una importante convicción de formar parte (hombre y naturaleza) del macrocosmos" (Levinton, 2009, p.46) Cabe destacar que la caza tenía un especial y complejo significado que incluía cuestiones genéricas, sociales y religiosas. Por un lado, como exclusivamente masculina, los cazadores destacados eran valorizados por toda la comunidad. Y desde el punto de vista religioso, existía una preparación previa al acto de cazar en la que el indio debía construir sus propios implementos y solicitar ser aceptado por los "dueños" de la naturaleza. Este profundo animismo marcaba pautas que, en definitiva, evitaban la simple depredación puesto que la caza no se trataba solamente de llevar carne a la aldea, sino que su espíritu religioso acompañaba el inicio y el final de la actividad con ceremonias rituales y le otorgaba un sentido que excedía la acción inmediata de cazar. Es más, en épocas de veda el área de caza o cazadero que pertenecía al espacio propio de cada parcialidad se respetaba y, sólo en determinadas circunstancias de necesidad, se compartía con otra parcialidad.

Así, el espacio vital se encontraba limitado por aguas y montes y se denominaba guára y se diferenciaba del tekoha, es decir, el espacio propio de la aldea. El guára se presentaba como una unidad socio-regional que aseguraba el derecho a la tierra cultivable y a la exclusividad de los cazaderos. Tekoha incluía la aldea, el monte y la chacra (habitado sólo por tres o cinco años, hasta que el agotamiento de la capa fértil obligaba a migrar la aldea). Sin embargo, "ese sitio no se abandonaba totalmente ya que permanecía en las vivencias de los indígenas porque allí dejaban fundamentalmente a sus familiares fallecidos (con excepción de los huesos de los grandes hechiceros que se trasladaban con el grupo). Es por ello que el ámbito de la residencia era considerado un lugar sagrado". (Levinton, 2009, p.149). El tekoha era el espacio en donde los hombres vivían de acuerdo a las tradiciones y en donde se integraban los emplazamientos viejos con los más recientes.

Como venimos comentando,

la región por donde se desplazaban los indios era proficua en ríos, arroyos y manantiales subterráneos. El agua ( $Y$ en guaraní) era el elemento vital considerado por el grupo étnico tupíguaraní como principio activo del universo o materia primordial. Así, el agua era fundamental para la alimentación y también para otros varios aspectos: como vía de movilidad para la navegación, como elemento imprescindible para la limpieza de los asentamientos (que incluía el baño como parte de la

\footnotetext{
3 "Es significativo el hecho de que hacían represas en los cursos de agua para capturar peces, anestesiándolos con sustancias extraídas de hierbas..." (Levinton, 2009, p.46).
} 
higiene), como organizadora de los espacios, como riego comunitario de los cultivos o hasta como contención de las estampidas (Levinton, 2009, p.45).

“Dentro del tekoha la chacra era también un lugar importante y las familias tenían a su cargo el cuidado de una superficie diferenciada de cultivo, además de la propia de trabajo comunitario" (Levinton, 2009, p. 225). "La aldea estaba formada por cuatro a ocho casas comunidades, generalmente dispuestas en cuadro a los lados de la plaza. Las familias emparentadas vivían en las malokas o casas grandes y tenían su kog o chacra de la que se ocupaban exclusivamente las mujeres". (González Torres, 1991, p.177) Por otro lado, dentro del tekoha la distribución de las tierras estaba dividida en dos áreas: el Amambaé que correspondía a las tierras individuales para la explotación familiar y el Tupambaé que consistía en las tierras en común.

El concepto de región (regionem) antes mencionado debe ser considerado como la porción de territorio determinado por circunstancias geográficas especiales y modificado por el hombre. Así, la región se basa en la relación entre una comunidad y un territorio con ciertas características físicas, climáticas, fluviales, etc. La región es, en definitiva, la suma, la síntesis y la reelaboración del paisaje. Por su parte, se entiende por Región Cultural al espacio organizado en función del aprovechamiento de los principales elementos naturales, por ejemplo, los ríos.

Ha sido, entonces, en la Región Cultural que comprende el sudeste de Paraguay, el sur de Brasil, el noreste de Argentina y el sudoeste de Uruguay que se produjo el encuentro entre indígenas y misioneros.

Esto derivó en la conformación de una macro-región que aunó las diversas micro-regiones (es decir, la extensión territorial de cada aldea) explotadas previa e históricamente por los indios por Derecho Natural. De esta forma, la Región Cultural representó la configuración de la macro-región con dos subregiones: la Provincia del Paraná y la Provincia del Uruguay. (Levinton, 2009, p.14)

\section{Posterior al contacto}

Partiremos del concepto espacial de micro-región puesto que nos interesa detenernos en la porción de territorio ocupado por la macro-familia. Será a partir de la observación de este espacio comunitario y, a la vez, individual que los padres jesuitas comenzarán a diagramar las misiones. De hecho, una vez identificados los cacicazgos, al momento de trasladar las poblaciones indígenas hacia el espacio misional los religiosos 
respetaron la espacialidad del tekoha como estructura básica socio-habitacional y la proyectaron a una escala mayor. Así, en un principio los padres ubicaron dentro de las misiones a varios caciques del mismo guára; lo cual llevó a que, con el paso del tiempo y el consecuente crecimiento demográfico, se encontraran conviviendo parcialidades indígenas de diferentes identidades étnicas. Situación que, salvo escasas circunstancias forzadas por una estrategia defensiva, no era habitual y ocurrieron inconvenientes.

Es de destacar también que los sitios escogidos para las distintas fundaciones de los nuevos asentamientos reduccionales fueron las antiguas aldeas de los caciques más importantes de las microregiones. Se buscaba, con esto, agrupar a la macro-familia para conservar las uniones sociales y el liderazgo.

Respecto de las aldeas indígenas es importante decir que, antes del contacto con los misioneros, existía un escaso vínculo entre sí, reduciéndose a circunstancias defensivas o alimenticias. Es por esto que el inconveniente que representaba la distancia entre los tekoha (en caso de necesidad) fue capitalizado rápidamente por los jesuitas con el fin de ofrecer a los indígenas un espacio nuevo, cerrado y protegido frente a los ataques de los portugueses. Por lo tanto, la nueva organización espacial cuasi urbana y marcadamente defensiva no hizo más que aportar una solución al indio que sufría una situación alterada por las violentas acciones de encomenderos y cazadores de esclavos.

En el proyecto de las nuevas organizaciones espaciales, las reducciones se distribuyeron, lógicamente, a semejanza de los poblados españoles siguiendo las Ordenanzas del Oidor Francisco de Alfaro de 1612 (en cuanto a traza y ejido). Es decir, se diseñaban manzanas rectangulares en las que se construían viviendas alargadas con huertas y corrales, un patio interno que daba al centro de la manzana y pertenecía a una familia. En el centro de la diagramación urbana se encontraba la plaza, punto de encuentro de toda la comunidad y en donde se celebraban las fiestas religiosas, como síntesis del hombre social y natural. De esta forma, los padres jesuitas continuaban la idea del orden y del cumplimiento de las normas a través de la construcción de un espacio habitacional planeado y organizado, siguiendo las pautas de lo que se consideraba "civilizado" en la época.

Sin embargo, entre los inconvenientes que los jesuitas detectaron tempranamente (y debieron resolver) apareció la anteriormente mencionada convivencia de una importante cantidad de cacicazgos 
(que, tal como dijimos, tenían escasos o nulos puntos de encuentro). Sin embargo, la solución a esta delicada situación social que podía malograr toda la experiencia misionera no provino de las Leyes de Indias, sino de los propios padres que recurrieron a herramientas tomadas de las costumbres indígenas: se apeló a la división del trabajo retomando las labores comunitaria (tupambaé) e individual/familiar (abambaé). Así, el tiempo se dividió, por un lado, en el trabajo para cada cacicazgo y, por el otro, en el trabajo de cada cacicazgo para la comunidad. Los frutos de este último se utilizaban para las compras comunitarias y el pago de los tributos. Será a partir de este punto que las misiones (en cuanto pueblos dentro de la colonia) comenzarán a distanciarse de las ciudades del virreinato que tenían su propia realidad administrativa y organizacional. Vale destacar que, además de la ya mencionada división del espacio para su explotación comunitaria e individual, otra gran diferencia con las urbes españolas era que la comunidad misionera no asumía individualmente el derecho de propiedad de las tierras donde se asentaba el pueblo, puesto que era considerada como propiedad colectiva.

En los comienzos el abambaé había sido ubicado en las proximidades del centro urbano bajo el control de los sacerdotes, pero debido al agotamiento de la tierra por el uso reiterado de las capas superficiales y la falta de herramientas, se requirió una mudanza periódica. Así, la ubicación de las chacras se fue alejando del pueblo (Levinton, 2009, p.229).

Esto resultó en otra importante modificación de la estructura típica del espacio indígena: la casa, la chacra y el monte que, previo al contacto, representaban una continuidad, debieron distanciarse entre sí. Por lo expuesto anteriormente, la chacra fue el primer sitio que se alejó. También debemos pensar en el monte que, lógicamente, quedó afuera de las empalizadas defensivas. Es importante destacar que en el monte quedaban los cazaderos, situación que, una vez más, trajo complicaciones entre los caciques. Los jesuitas resolvieron esta situación apelando a la adaptación de los indígenas al nuevo espacio en construcción. Así, se incorporaron los cazaderos de la macro-familia al territorio de la comunidad que, paulatinamente, asumía características urbano-rurales.

Debemos decir que, frente a las dificultades señaladas, los religiosos acertaron de manera extraordinaria en la observación de la importancia que poseía cada elemento natural para los indígenas. Así, fueron resolviendo las diferentes situaciones problemáticas que surgieron respecto del territorio $y$, particularmente, del agua. En cuanto a este último elemento ya hemos señalado que la conformación del espacio vital estaba delimitada y asociada con los cursos de agua. Esta representación de la naturaleza que conllevaba un universo simbólico fue también rápidamente replicada por los jesuitas en la ubicación de las 
misiones. De esta forma, el nuevo espacio repetía de alguna manera el hábitat anterior de interrelación hombre / naturaleza. Y, a través del agua, se alcanzó la identificación del nuevo territorio con el anterior ya que ambos compartían el elemento agua como ordenador. Así, los estudiosos ${ }^{4}$ han identificado los antiguos pueblos misioneros por las vías de agua que los atravesaban. Algunos ejemplos de ello son: la reducción de Yapeyú (arroyo Tapebicuá, cañada del Ombú y arroyo y bañado Guaviraví); la reducción de San José (arroyo Pindapoy Grande y otros arroyos menores); la reducción de San Carlos (los brazos del río Aguapié y arroyo Pindapoy); la reducción de Candelaria (arroyos Agrupa y Anselmo); la reducción de San Ignacio Miní (arroyos Yabebiry y Persiguero); la reducción de Santo Tomé (arroyos Itá-Curá y Cambia) y la reducción de Apóstoles (arroyos Chuniray, del Potrero y Cuña Maño)

\section{La construcción urbanística. La ciudad "a cordel y regla"}

La política colonial de la diagramación y fundación de las ciudades en la región sudeste de Sudamérica resultó necesariamente definitoria para las futuras misiones jesuíticas de las sub-regiones del Paraná y el Uruguay. Desde los inicios de la acción colonizadora el reino de España estructuró su imperio como una red de ciudades interconectadas e impuso a los diferentes grupos humanos que las habitarían el objetivo de conformar una nueva sociedad que debía seguir pautas culturales que pretendían ser homogéneas respecto de la Península. Sin embargo, es lógico considerar que los iniciales caseríos -luego devenidos en ciudades- poseyeran desde sus inicios una estructura defensiva que buscaba ordenar ideológica y jerárquicamente a poblaciones muy diversas. Del mismo modo, en su interior se escondía el riesgo del mestizaje y la aculturación cuya consecuencia inmediata ponía en riesgo el poder hispánico, monárquico y cristiano.

Es por esto que la idea de alinear el vasto mundo colonial americano con el mundo metropolitano pretendía reducir al primero a la categoría de sociedad dependiente que no debía reconocer su diferenciación respecto de cualquier ciudad española en donde residiera la Corte. Así, necesariamente las ciudades intercomunicadas del Nuevo Mundo se mostraron disciplinadas a una ideología que seguía la cuarta ley ignaciana "Perinde ac cadáver". Aunque, en realidad, poseían un mundo socio-cultural inequívocamente distinto al de la metrópoli y lo cotidiano estaba plagado de dificultades conformadas -entre otras- por la presencia de enemigos, hambrunas y enfermedades. (Romero, 1986, p.69).

Luego del acto fundacional, en el plano, las ciudades americanas comenzaban a ordenarse en lo

\footnotetext{
${ }^{4}$ Levinton, 2009, p. 49.
} 
espacial y social. En su diseño se seguía un sistema geométrico como proceso de abstracción del pensamiento ideal y, por lo tanto, perfecto. Así, "la forma en damero fue la adoptada por las urbes coloniales, elemento regulador que imponía un orden riguroso que evidenciaba la jerarquía social" (Rama, 1998, p.20). De esta forma se insertaba un marco ideológico que controlaba las actividades sociales y sistematizaba la actividad humana. La disposición reflejaba, entonces, la razón ordenadora. Además, la geometría distributiva del plano de las ciudades revelaba su dinámica de interacción humana. Por lo tanto, la nueva sociedad estaría basada en una rígida estructura jerárquica. Pero, a pesar de que estos lineamientos estuvieron firmemente presentes en las fundaciones, el espacio americano constituyó, de todas formas, una oportunidad para construir en sus geografías otros espacios ideales.

Debemos destacar que las urbes se edificaron como sitios cerrados (concepto que no implica necesariamente muros físicos) para defender y sostener -junto con la metrópoli- la hegemonía de la arquitectura, de la distribución en el plano, de las clases sociales y de las pautas político-culturales. El "extra muros" del espacio contenía una naturaleza humana y geográfica incompatible con los cánones de la civilización ordenada y, por lo tanto, las instituciones vivían a sus espaldas puesto que resultaba una amenaza potencial.

\section{La reducción como nuevo modelo de orden}

La gradual construcción de las reducciones jesuíticas que pertenecieron a la Gobernación del Paraguay y del Río de la Plata fue encarada, como era de esperarse, siguiendo la misma distribución espacial que el resto de las ciudades coloniales ya que esto significaba alinearse con las políticas virreinales e introducir a los indígenas a un modo de vida guiado por la razón. De esta forma, a partir de 1587 (momento en que el padre Claudio Acquaviva, General de la Orden, decidió crear nuevas reducciones en la región del Paraguay) la fundación de las misiones estuvo incluida dentro del mismo plan civilizador que la monarquía española imponía como pauta de control.

La disposición espacial interna de estas poblaciones marcaba una importante diferencia respecto del exterior, puesto que en el "adentro" se obedecía a un espacio ordenado y seguro frente al peligro y el caos del "afuera". Esta idea de delimitar perfectamente ambos sitios estaba reforzada por signos como el portal de acceso y los muros que rodeaban a la reducción. Esta estructura que protegía el interior respondía a uno de los objetivos jesuitas: acercar a los indios a la fe por medio del orden dentro del espacio habitacional que, 
por otra parte, debía alcanzar también a todo un estilo de vida. Es decir, se accedería a la religión a través de una vida reglada en la que primaría la reflexión de los actos individuales. Esto conduciría a la reorganización de la realidad física viabilizada por un diseño urbanístico ordenado y mediatizado por signos que respondían a la cultura razonante.

Nos interesa develar el lenguaje simbólico que subyace en la construcción de las reducciones y que busca revalorizar la uniformidad en los treinta pueblos misioneros. Para ello nos centraremos, en primer lugar, en el orden físico de las misiones, es decir, abordaremos los planos como reproducciones intelectuales de una realidad modélica. Luego, nos dedicaremos "al orden de los signos que, de por sí, manifiestan perennidad" (Rama, 1998, p.28) para centrarnos, a continuación, en el nivel propiamente simbólico ${ }^{5}$. También analizaremos la cuestión espacial a partir de los conceptos de utopía y heterotopía ${ }^{6}$ para, finalmente, realizar una lectura hermenéutica interpretativa de la composición que alcanzaron las urbes/reducciones observando las mutuas adaptaciones culturales que existieron entre padres y guaraníes.

Tal como comentamos unas líneas más arriba, tanto las ciudades coloniales como las misiones se iniciaron como sitios defensivos dentro de los cuales se respiraba el espíritu de la polis como marco civilizador que diferenciaba el "adentro" del "afuera". Dichas reducciones fueron sitios aislados en un espacio inmenso marcado por un ambiente que se mostraba francamente hostil. Por dentro las misiones poseían una doble función educativa y evangelizadora. Estaban amparadas no ya por la monarquía, sino por la Iglesia que, de manera similar -aunque con diferentes objetivos-, buscaba disciplinar a sus habitantes.

Las reducciones aparecían en el paisaje como un espacio construido en el medio de un enorme ambiente deshabitado. Estos sitios surgían entre los montes, linderos a los cursos de agua y a las sierras como un espacio cuasi irreal, como remedio a la agresión y desprotección exterior. A su vez, esas construcciones urbano-rurales fueron $-y$ aún lo son- perfectamente reales $y$ su vestigio, historia e importancia nos llegan luego de poco más de dos siglos. Bajo la tutela de los padres jesuitas constituyeron en sus ciento cincuenta años de existencia espacios diferentes, defensivos y ordenados. También fueron el objeto de la codicia de esclavistas portugueses y de la envidia de vecinos de la colonia hispánica. Representaron para algunos un espacio mítico y, a la vez, real respondiendo a un tipo de pensamiento

\footnotetext{
${ }^{5}$ Trabajaremos sobre obras de Paul Ricoeur "Hermenéutica y Acción”, “El discurso de la acción” y Tiempo y narración: Configuración del tiempo en el relato histórico".

${ }^{6}$ Nos remitimos a Tomás Moro, Campanella “Utopías del Renacimiento" y Foucault "Des espaces autres".
} 
utópico renacentista.

También es necesario recordar que en su esencia los ideales utópicos conllevaron un proyecto que involucraba cuestiones sociales, religiosas, urbanas, políticas e históricas. Desde esta perspectiva es posible hallar un paralelo entre el espacio utópico y el de las reducciones, con la única salvedad de que en los discursos utópicos nunca se pasó al plano de la acción. En cambio, las reducciones se constituyeron como urbes desde el acto fundacional, la concreción edilicia y el funcionamiento.

Es por esto que al hablar de los pueblos jesuíticos podríamos decir que resulta insuficiente y hasta casi contradictorio relacionarlas con una utopía puesto que, como venimos afirmando, constituyen una circunstancia real, concreta, identificable y perdurable ${ }^{7}$. Así, consideramos que el concepto de utopía no es el que más se ajusta a la realidad que representaron los treinta pueblos misioneros.

Las reducciones comenzaron como una idea que llegó a constituirse en una realidad. El denodado y tenaz trabajo de padres e indios hizo posible crear un espacio concreto, reconocible y con identidad propia ${ }^{8}$. Y es por esto que, en la búsqueda de una idea que sustente teóricamente el fenómeno de las reducciones, hemos apelado al concepto de heterotopía ${ }^{9}$. Realizaremos, entonces, el análisis y la descripción sistemática de nuestro objeto de estudio: las reducciones, observadas como espacios diferentes que, por sus características y, a raíz de circunstancias temporales, generaron sobre sí mismas una percepción mítica.

Desde su concepción, desde la propia idiosincrasia que las pergeñó, las misiones tuvieron características que las hicieron sitios peculiares: 1) funcionaban como una sociedad dentro de la sociedad colonial; 2) creaban un espacio otro, real, meticuloso y ordenado, de características casi perfectas; 3) suponían un sistema cerrado que las aislaba y, a la vez, de apertura que las hacía penetrables ${ }^{10}$ y 4 ) en un mismo lugar real se yuxtaponían varios espacios (por ejemplo, jardines, huertas, cementerios, plazas) que

\footnotetext{
${ }^{7}$ Tenemos en cuenta a las misiones jesuíticas en la situación actual, es decir, como ruinas, lo cual les otorga, justamente, la característica irrefutable de su existencia en el pasado y de signo evidente en el presente. Utopía ha sido el lugar del proyecto. El ou-topos como espacio ideal siempre está ubicado "más allá", es un "lugar que no hay" pero adonde podría irse porque es un lugar, aunque no se halla, en el mundo inteligible de este mundo terreno y lugareño (Ímaz, 1995, p.13). "La dificultad de arribar a él indicaría su directa relación con la imposibilidad de concretarse, de construirse, de montarse, de ponerse en práctica, etc." (Del Percio, 2011).

8 "...lieux reéls, de lieux effectifs, de lieux qui ont dessinés dans l'institution même de la societé, et qui sont des sortes de contre-emplacements,..." (Foucault, 1967, p.4).

9 "Ces lieux, parce qu'ils sont absolument autres que tous les emplacement qu'ils reflètent et dont ils parlent, je les appellerai, par opposition aux utopies, les hétérotopies;..." (Foucault, 1967, p.4).

${ }^{10} \mathrm{Si}$ bien eran espacios al que se podía acceder, sólo se podía ingresar con un permiso.
} 
recreaban, a su vez, microespacios.

1) Las reducciones de las regiones del Guayrá, Itatín y Tape; del Uruguay; Paraná y Chaco pertenecieron al virreinato del Perú hasta principios del siglo XVII, momento en que pasaron a depender de las Gobernaciones del Paraguay y del Río de la Plata. Sin embargo, a pesar de hallarse a gran distancia de las ciudades de españoles y criollos estaban unidas bajo un mismo concepto administrativo, ideológico y hasta tributario. Pertenecían a la red de urbes que conformaban la sociedad colonial sudamericana.

Los pueblos misioneros tenían vínculo con las ciudades más próximas como Asunción o Buenos Aires, pero funcionaban de manera diferenciada. Podríamos decir que existían de manera paralela. Sin embargo, eran contempladas y consideradas como pertenecientes a la sociedad colonial ${ }^{11}$.

2) Ya nos hemos referido al orden con que fueron concebidas las reducciones, en virtud de un funcionamiento preciso y determinado de muros para adentro y, también, de sincronía cultural y productiva dentro de la sociedad. Además, las misiones lograron un notable nivel de rendimiento que, en determinado momento, llegó a opacar la productividad de las propias ciudades.

Por otra parte, no podemos olvidar el progresivo crecimiento que alcanzaron las reducciones en cuanto a red vial y fluvial con el objetivo de intercomunicarse, autoabastecerse y defenderse. Y el orden con el que había sido organizada cada misión contemplaba un tipo de productividad que explotaba la riqueza natural según el contexto geográfico que tuviera la zona. Esta especialización económica le daba autonomía y también propiciaba el intercambio y la ayuda entre los diferentes pueblos. Pero sobre todo, el orden y el control de parte de los padres generaron sobreproducción, con lo cual las reducciones llegaron a hacer acopio de verduras y yerba mate (siendo muy famosos los yerbales.) Del mismo modo, se destacaron las vaquerías en donde el ganado se multiplicaba (Vaquería del Mar, Vaquería de los Pinares, Vaquería del Río Negro $^{12}$ ) y cumplieron un rol esencial en la economía regional. El caso prototípico y que, por otra parte, fue el único que pudo autosustentarse por completo, fue la reducción de Yapeyú que llegó a tener seis estancias

\footnotetext{
11 “...chaque hétérotopie a un fonctionnement précis et déterminé à l'interieur de la société, et la même hétérotopie peut, selon la synchronie de la culture dans laquelle elle se trouve, avoir un fonctionnement ou un autre." (Foucault, 1967,p. 5)

12 Vaquería del Mar: se hallaba en los actuales Departamentos de Lavalleja, Treinta y Tres y Cerro Largo, Uruguay. Vaquería de Ios Pinares: lindaba al norte con el río Uruguay, al oeste con el bosque y al sur y al este con la Sierra General. Vaquería del Río Negro: se encontraba entre los ríos Negro, Uruguay y Queguay. (Levinton, 2009)
} 
de ganado en $1694^{13}$.

3) Las reducciones se caracterizaban por su aislamiento, es decir, sostenían un sistema de cierre pero, a la vez, también representaban un espacio de apertura. Nacidas como espacio defensivo, se encontraban cerradas y ejercían un importante control de quién ingresaba y de quién salía. Paralelamente, se hallaban abiertas a recibir a todo aquel que quisiera abrazar la fe cristiana y a seguir pautas de civilidad y trabajo bajo la atenta mirada de los padres ${ }^{14}$.

En el "adentro" se trabajaba diariamente para alcanzar y sostener un espacio ordenado, reglado por las horas de los rezos y el toque de la campana. Es decir, cuando sonaba la campana, todos debían cumplir con sus obligaciones: despertar, rezar, comer, trabajar, estudiar, cumplir con las obligaciones maritales, dormir. Nada estaba librado al azar.

4) Considerar las reducciones como heterotopías dentro de la sociedad colonial nos lleva a observar también el espacio interior de las misiones en el que aparece la yuxtaposición de varios espacios. Esta cuestión, que desarrollaremos más adelante, será nodular para nuestro trabajo. A modo de ejemplo mencionaremos algunos espacios que resultan representaciones de diversos microcosmos ${ }^{15}: / p^{2}$ laza/, /jardín/, /cementerio/, /iglesia/, etc.

\section{El espacio reduccional}

Al considerar el espacio reduccional debemos centrarnos lógicamente en el vínculo que existió entre padres e indios. Esta interacción generó una serie de propuestas y resistencias que produjo con el tiempo mutuas adaptaciones que concluyeron modificando tanto a unos como a otros. Consideramos éste como el centro de la cuestión de la conformación espacial de las misiones y su punto de partida consiste en una situación concreta que define a todo sujeto: su vivienda.

Ya nos hemos referido a que previo al contacto los indígenas vivían en casas (malocas) que se

\footnotetext{
13 “... un autre espace, un autre espace réel, aussi parfait, aussi méticuleux, aussi bien arrangé (...) colonies merveilleuses, absolument réglées, dans lesquelles la perfection humaine était effectivement accomplie." (Foucault, 1967, p.8)

14 "Les hétérotopies supposent toujours un système d' ouverture et de fermeture qui, à la fois, les isole et les rends penetrables". (Foucault, 1967, p.7)

${ }^{15}$ “L'hétérotopie a le pouvoir de juxtaposer en un seul lieu réel plusiers espaces, (...) Le jardin traditionnel des persans était un espace sacré qui debatí réunir à l'interieur de son rectangle quatre parties représentant les Quatre parties du monde, avec un espace plus sacré encore que les autres qui était comme l'ombillic,..." (Foucault, 1967, p.6)
} 
agrupaban en aldeas. Sin embargo, la posesión de la vivienda no se reducía a los estrictos límites de la aldea, sino que se ampliaba con la chacra (ubicada en las proximidades) y se extendía más aún al monte, espacio en donde se concretaban las actividades de caza. Con lo cual el espacio habitacional indígena, casa-chacramonte, fue modificado post-contacto misionero. Es decir, en el traspaso a la reducción se produjo una profunda adaptación que llegó a modificar no solamente la casa sino todo el espacio a su alrededor.

Desde los inicios los jesuitas permitieron que las macro-familias se instalaran en las reducciones de la misma forma que lo hacían en las aldeas: construyendo viviendas alargadas que, por iniciativa de los padres, comenzaron a tener divisiones internas. Como en el pueblo misional ingresaban varios caciques -a fin de evitar rencillas de poder- se organizó el espacio separando las casas de indígenas y de caciques. De la misma forma las casas de los padres también se encontraban diferenciadas marcando una separación física.

El diseño del esquema de los pueblos fue el mismo para todos: la plaza constituía el centro del poblado y por ello dividía el espacio en dos secciones (imagen 1): una inferior, es decir, más cercana al portal de acceso y otra superior, alejada del ingreso. En la parte inferior se ubicaban las casas de los indios, el cabildo y las casas de los caciques. En la parte superior se observaba la huerta/jardín, la residencia de los padres, el colegio, la iglesia, el cementerio y el cotiguazú. Dentro de este espacio el núcleo central lo constituía, lógicamente, la iglesia (imagen 2). La división del esquema reduccional en dos porciones será la base sobre la cual analizaremos los componentes simbólico-culturales sobre los que se construyó el espacio.

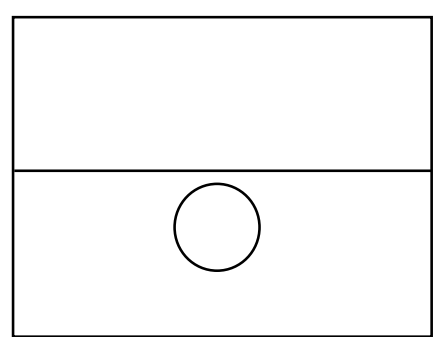

(imagen 1)

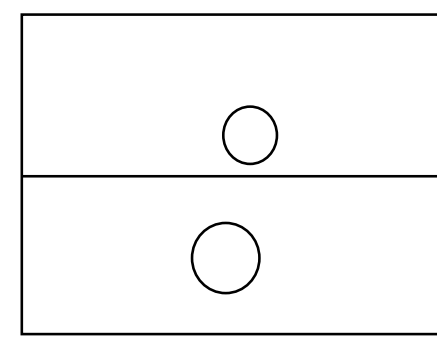

(imagen 2)

\section{El espacio de abajo:}

En la gradual transformación que llevó a la aldea a convertirse en un pueblo, la ubicación de las casas de los indios alrededor de un espacio abierto fue meditada y calculada. Ese sitio que ocupaba la parte 
central del espacio inferior poseía una gran cruz y se conformó en la plaza. Así, la disposición que tuvieron todas las reducciones alrededor de la plaza rectangular estuvo guiada por la idea de construir una pequeña ciudad, más exactamente, una urbe-rural. La plaza se presentaba en el medio de las casas como el centro del pueblo, era el núcleo de la vida cristiana. Allí se realizaban fiestas y procesiones. Constituía una proyección de la propia iglesia que se encontraba a continuación, más arriba. Dicho desplazamiento del espacio eclesial a otro abierto tenía el objetivo de otorgarle a la plaza un sentido sagrado. Será en este otro espacio (plaza) en donde se producirá el encuentro de todos los habitantes, aunque sin las diferencias marcadas por el atrio, el púlpito y los asientos. Toda la población de pie circulaba alrededor de la cruz: padres e indígenas marchaban en las festividades religiosas unidos en la oración. Por otro lado, era en la plaza en donde los indios tenían un rol protagónico que los acercaba a los padres al cargar, por ejemplo, la imagen del santo patrón o de la Virgen. Así, la plaza era una especie de centro, de espacio nuclear de toda la reducción y su cruz sobreelevada por encima de los hombres hacía que se cambiara la percepción "horizontal" (propia de la cultura indígena) por otra de tipo "vertical” cristiana ${ }^{16}$.

\section{El espacio de arriba:}

En cuanto al espacio superior, éste estaba conformado por la iglesia, las habitaciones de los padres y el huerto. Sobre la porción derecha se hallaba el colegio y a la izquierda, el cementerio. Y, compartiendo el mismo plano superior, se hallaba el cotiguazú ${ }^{17}$. Si bien resulta evidente que la iglesia representaba el espacio privilegiado "de arriba", no podemos dejar de señalar que el huerto o jardín también fue un espacio particularmente importante tanto para padres como para indígenas. En una primera instancia las notorias semejanzas del huerto/jardín con un sitio paradisíaco guardaban directa relación con las concepciones religiosas cristianas y paganas ${ }^{18}$.

Ya hemos comentado que el modo de vida indígena tenía estructuralmente incorporada la presencia del agua. De hecho, hemos mencionado que las aldeas estaban ubicadas cerca de espejos de aguas y que los padres al realizar el traslado y transformación de las aldeas en pueblos misioneros replicaron la composición

\footnotetext{
${ }^{16}$ Ruiz, I. "Las caída de los dioses y la dulcificación del mar: Secuelas de otra mirada sobre la arquitectura Mbyá-Guaraní" en: Revista de Indias 230 (2004), pp.101-108.

${ }^{17}$ Este edificio constituía la casa de retiro para mujeres viudas, madres con hijos, ancianas, jóvenes y aquellas que no quisieran formar una familia. Resulta interesante observar su ubicación en el plano, próxima de los padres y marcadamente distanciada de las familias y, en particular, de los hombres.

${ }^{18}$ Cuando los jesuitas entablaron contacto observaron que, dentro de la cosmovisión cultural aborigen, existía un importante desarrollo míticonarrativo acerca de un sitio conocido como la "Tierra sin Mal". Será a partir de este concepto que los padres comenzarán una acción de intercambio y adaptación que concluyó -como síntesis de interpretación- en el otorgamiento de un lugar destacado para el huerto/jardín en las reducciones.
} 
espacial: pueblo / curso de agua. La primera reflexión al respecto se orienta a considerar el río a partir de una perspectiva práctica que lo coloca como vía de comunicación. En segundo lugar recordemos que los indios utilizaban el agua para su higiene personal en baños comunitarios y cotidianos. A pesar de que los padres rechazaban este hábito por sus concepciones morales, no pudieron erradicarlo y en las reducciones decidieron adaptar la costumbre del baño bajo "normas civilizadas" que contemplaba un sitio adecuado, un momento determinado y la separación de hombres y mujeres. Esta es una de las causas por las que se observa en los planos reduccionales al agua como un elemento más de ordenamiento espacial, puesto que los padres, en una acción de ingeniería, acercaron el agua de arroyos y ríos a la planta urbana. Así, pasaron a formar parte de la geografía misionera (en la porción superior del plano) las fuentes, las pilas, los chafarices. Además, crearon un interesante sistema de recolección de agua de lluvia que, sumado al transporte subterráneo, conformaba una red de desagües cloacales ${ }^{19}$.

Otro elemento propio de la cosmovisión indígena y que fue considerado por los padres fue la asociación entre naturaleza y hombre ya que todo en su conjunto se asumía como una "eco-cosmología". Por lo tanto, la convivencia humana debía desarrollarse en un espacio de armonía con los elementos naturales, respetando especialmente sus ciclos. En relación con esto, dentro de la religión de los tupíguaraníes existía el concepto de paraíso como espacio ideal, es decir, un sitio en donde desaparecían los sufrimientos y los esfuerzos. Este lugar llamado "Tierra sin Mal", concebido como un punto geográfico concreto en este mundo, era la gran aspiración de todos los sujetos y, por ello, emprendían numerosas y prolongadas peregrinaciones en su búsqueda. En las tradiciones orales relatadas por los karaí o profetas encargados de guiar al pueblo, la Tierra sin Mal se presentaba como un espacio de fertilidad excepcional, un lugar privilegiado "indestructible, donde la tierra produce por sí misma sus frutos"20. En definitiva, este paraíso era "nuevas tierras en donde se halla inmortalidad y descanso perpetuo" ${ }^{21}$ y allí la tierra es "hermosa, en la cual todas las cosas vendrían naturalmente a pedir de boca, sin que hubiera esfuerzo ni trabajo." ${ }^{22}$ El signo físico característico de semejante lugar promisorio era la profusión de árboles frutales y la abundancia de ríos. Esta imagen, reflejo del espacio edénico, debió sensibilizar a los padres ya que era posible asimilarlo a la representación cristiana del Paraíso.

\footnotetext{
${ }^{19}$ En la reducción de Mártires si bien no se distingue el modo de llegada del agua, se advierte la existencia de tres de las llamadas lagunas artificiales ubicadas detrás de la iglesia, a un costado de las viviendas y en un ángulo de la traza. (...) En Santa Rosa había, por lo menos, una laguna que se hallaba inmediata al pueblo. (...) La existencia de un chafariz en el pueblo de San Nicolás era una fuente que, por cañerías, llevaba el agua hasta el núcleo urbano aprovechando la inclinación del terreno. En los asentamientos de San Miguel y San Lorenzo se encontraron fuentes que tenían un sitio determinado para colocar los cántaros (zafariches o lugar donde poner los cántaros= cantarera) y recibir el agua que salía por la boca de sus esculturas de ángeles. (Levinton, 2009, pp.51-52).

${ }^{20}$ Clastres, 1989, p.34.

${ }^{21}$ Clastres, 1989, p.35.

${ }^{22}$ Clastres, 1989, p.35.
} 
De esta forma, en el imaginario urbano rural con que fueron concebidos los pueblos misioneros tuvo una especial relevancia el paisaje. Padres ${ }^{23}$ e indios hallaban dentro de la reducción sitios que reproducían la alegoría del Paraíso acentuado por la presencia de agua, árboles frutales y una gran cruz. No se trataba solamente del simbolismo de la iglesia -casa de Dios- y la plaza como ámbito procesional cargado de trascendencia, "había en la arquitectura de las misiones una concepción espacial de un mundo mejor 'aquí y ahora' ${ }^{\prime 24}$ que expresaba que la concreción del paraíso era posible en un espacio real.

\section{Los componentes simbólico-culturales}

Tal como venimos exponiendo, todos los pueblos fueron diseñados con una disposición rigurosa alrededor de la plaza rectangular que se encontraba a continuación de la iglesia. Podríamos representar la primera división del espacio $(1+1)$ como una marca de orden, equidad y equilibrio, recordando la división antes marcada entre el espacio de "arriba" y el espacio de "abajo".

Luego, en cuanto al espacio superior aparece una segunda partición en dos planos $2+2$ (imagen 3) que se replica en el espacio inferior $2+2$ (imagen 4).
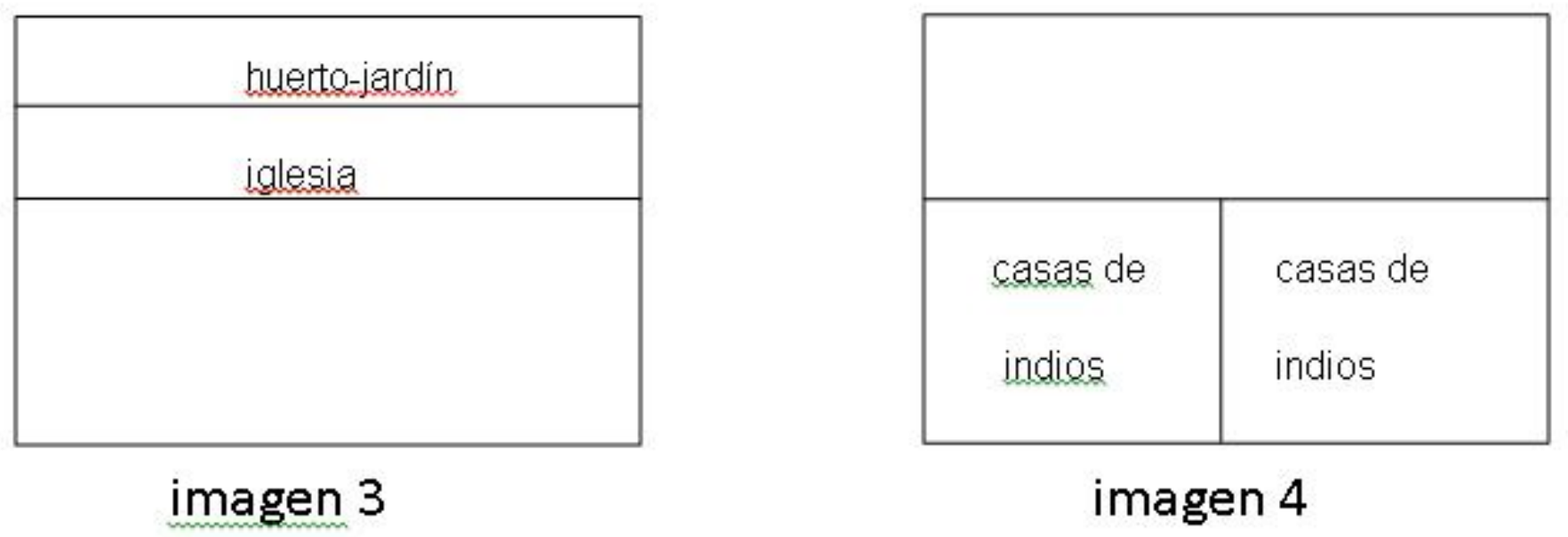

\footnotetext{
${ }^{23}$ Recordemos también la tradición cultural medieval de raíz musulmana que aportaron los padres respecto de la imagen del Paraíso. Según Burkhart al citar al Corán dice: "el Paraíso es un vergel por el que corren riachuelos..." Es la misma imagen edénica transmitida por el Antiguo Testamento. (Burkhart 1992:77-96) Rubiera Mata también habla de la descripción coránica del paraíso, la ciudad ideal: oasis atravesado por ríos y acequias con profusión de árboles frutales. (Levinton, 2009, p.55)

${ }^{24}$ Levinton, 2009, p.55.
} 
Y si realizamos un nuevo acercamiento a la planta podemos identificar otra división $4+4$ tanto en el espacio superior (imagen 5) como en el inferior (imagen 6):

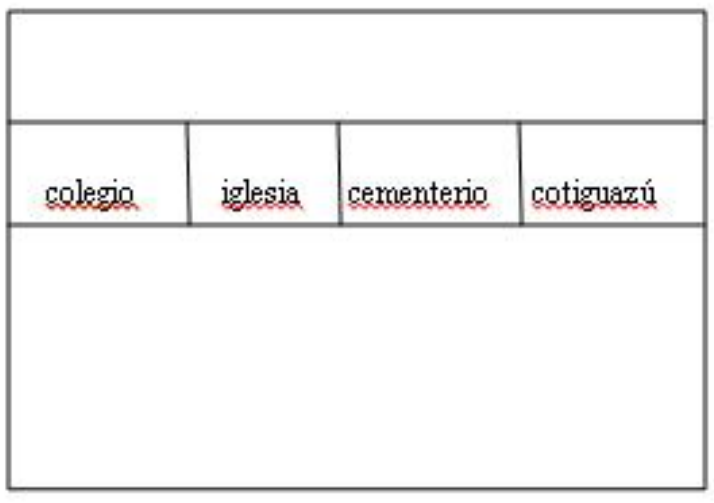

imagen 5

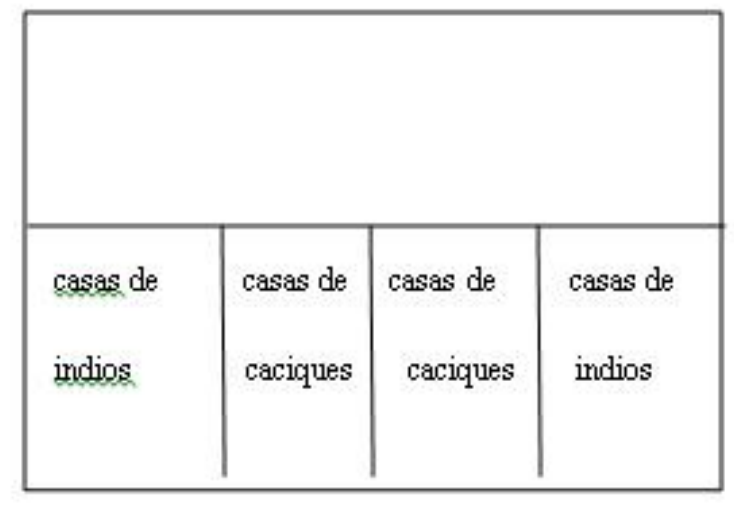

imagen 6

Hasta ahora nos hemos referido exclusivamente a las diversas particiones internas que pueden ser observadas en el plano de las misiones. Hemos señalado que se presentan en una progresión ascendente, partiendo de una concepción interna hasta llegar a representar la estructura externa (imagen7) que, de manera general, poseían los pueblos.

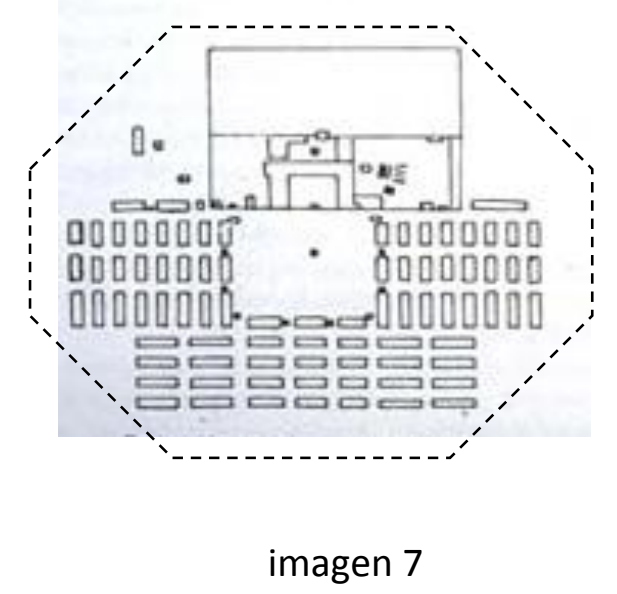

(Plano de reducción San José de Chiquitos)

La figura que circunvala el espacio exterior de la misión representa un octógono. El ocho como base de ordenamiento cobra un relieve especial debido a la importante significación que ha tenido para el cristianismo. El cuatro duplicado forma la figura octogonal que aglutina otras dos: el círculo y el cuadrado representando el orden celeste y el orden terrestre, respectivamente. Es en esta combinación en donde se 
produce la estabilidad en la vida material. El octógono indica, por lo tanto, regeneración, una nueva vida marcada por el abandono de lo contingente y una tensión hacia lo eterno. En esta tensión de dos extremos el círculo y el cuadrado refieren a la unión indisoluble del espíritu y la materia. Finalmente, el número ocho aparece también en el octavo día de la creación y se considera simbólicamente como la resurrección de Cristo, es decir, el inicio de una nueva etapa de la vida terrenal a partir del conocimiento de la vida trascendente (libre ya de ataduras y sufrimiento). Es, además, símbolo de equilibrio y de vida eterna en lo que tiene de progresión ascendente $(2,4,8,16,32$, etc.). Dentro de la estructura que presenta el plano de las misiones aparece una perspectiva simbólica basada en la idea de que estos poblados constituían el lugar ideal para el desarrollo del hombre cristiano en sociedad. Así, el pueblo se conformaba como un emplazamiento religioso y cultural que procuraba que los indios alcanzaran una vida política, humana y de fe.

\section{"A cruz y campana". El ser indígena cristiano y el nuevo espacio}

A partir de la particular configuración espacial de cada micro-región se proyectaron las fundaciones de los pueblos misioneros. En sus orígenes estos centros urbano-rurales fueron delineados siguiendo las ya mencionadas Ordenanzas de Alfaro y pretendieron semejarse a las ciudades españolas: cuadras o manzanas rectangulares en donde viviendas compartimentadas tenían internamente patio con huerta y corral. Sin embargo, esta composición espacial inicial no coincidía con el modo de vida indígena que tendía a un esquema de tipo comunitario. Será por ello que luego de transcurridos alrededor de diez años del proceso de establecimiento de las reducciones, los jesuitas introdujeron un cambio esencial. Se modificó la traza de las misiones eliminando los patios individuales y las divisiones internas de las viviendas-manzanas; así, esta conformación se aproximó más a las antiguas aldeas indígenas. Este último cambio, en particular, se debió a "la comprobación -por parte de los padres- de la existencia de normas de conducta tradicionales indígenas por las que se castigaba el adulterio y se evitaban los divorcios" (Levinton, 2009, p.151). En las modificaciones también se ampliaron las calles y, principalmente, la plaza como núcleo de la vida en común.

En la tarea expansiva y de crecimiento de las reducciones, los jesuitas entendieron que para sobrevivir autónomamente la población debía crecer hasta alcanzar un mínimo de 1000 habitantes. Esta situación obligó a trasladar los sembradíos fuera de las reducciones y a ubicar el ganado en estancias o "vaquerías" que abastecerían de carne a todos los pueblos. Estas modificaciones tendientes a eliminar una estricta cuadrícula espacial (propia del discurso hegemónico monárquico) tuvieron un mensaje claro y 
evidente para los indígenas: los pueblos misioneros se diferenciaban de las ciudades españolas, no compartían la misma pauta cultural y esto les otorgaba una cierta libertad. Se volvió, entonces, al antiguo esquema estructurante: casa/chacra/monte lógicamente con sus controles y adaptaciones. Si bien el concepto de "monte" quedaba excluido de la vida reducida (ya que ésta evitaba la libertad del indio cazador considerada innecesaria y propensa al vagabundeo), los padres debieron adaptar el rol masculino al nuevo espacio. Para ello los religiosos trabajaron en el espacio "chacra/huerta" porque aglutinaba, a la vez, el sustento para las familias y una representación de la naturaleza. Es decir, a través del contacto directo de los indios con la vegetación era posible asociar ese huerto como símbolo del universo. De ahí que en las reducciones resultaran tan sugestivos los espacios destinados a la huerta y al corral comunitarios, en donde los frutales plenos de colorido se asociaban en su fertilidad y belleza al concepto que los indígenas tenían del paraíso. Así, la presencia de los árboles frutales y fuentes constituían tanto para padres como para indios un espacio de especial simbolismo ${ }^{25}$.

Debido, entonces, a la gran demanda alimenticia "los indios encargados de cuidar los sembradíos se trasladaban a caballo, bajo la estricta vigilancia de los jesuitas. Y, una vez finalizada la tarea, regresaban a la misión. Esta actividad con su desplazamiento le otorgaba un nuevo rol social resultante de una adaptación: si bien la tarea antiguamente era realizada por mujeres, bajo el sistema de reducciones el hombre será el que podrá salir y, especialmente, el uso del caballo" ${ }^{26}$ marcará la diferencia con las actividades femeninas. Como resultante de estos cambios la mujer que se encargaba anteriormente de la chacra dentro del espacio reduccional vio su tarea aliviada. Sus nuevas actividades requerían menor esfuerzo puesto que se trataba de cestería o tejidos. Esta situación hizo que las indias fuesen un importante elemento de cohesión entre el antiguo ser indígena y el nuevo.

El ser indígena cristiano aceptó modificaciones respecto del anterior estilo de vida. En algunos casos hubo disidencias y negativas, en otros casos las mujeres ayudaron a los hombres a propiciar el cambio. Pero siempre la mirada atenta de los padres supo capitalizar los componentes simbólicos que todo individuo posee como estructurante de su pensamiento.

\section{Conclusiones}

\footnotetext{
${ }^{25}$ En el pueblo de San José y en San Francisco Xavier había una capilla con una huerta cerrada con palos a pique cuyas medidas eran de tres cuadras y presentaban "un monte de duraznos, un mandiocal, tabacal y otras plantas medicinales." (Levinton, 2009, p,55)

${ }^{26}$ Levinton, 2009, p. 241.
} 
El antropólogo francés Marc Augé afirmó que el espacio de la antropología es necesariamente histórico ya que se trata precisamente de un espacio cargado de sentido por los grupos humanos. El encuentro de los diferentes símbolos de los padres jesuitas como de los indígenas fue el primer punto de contacto a partir del cual se produjo la convivencia de ambas culturas en tierras sudamericanas. Será sobre la base de esos símbolos que se cimentará el encuentro de identidades de los dos grupos humanos y, a partir de los cuales, surgirá la voluntad de construir espacios en común.

Debido a la desventajosa situación que vivían los indios frente al avance portugués, el importantísimo cambio espacial que impulsaron los jesuitas favoreció la edificación de una comunidad que sumó elementos nativos al universo cultural de los religiosos, reunidos ambos en la firme tarea de acoger la fe. Y, a pesar de haber trasladado su entorno habitacional a la misión, el indígena se siguió reconociendo a sí mismo porque en el nuevo espacio todo se había transformado por sugerencia de su sacerdote jesuita. Más adelante, cuando la aldea pasó a ser un pueblo, el indígena que vivía en esa ciudad con cabildo y plaza continuó ligado a su antiguo espacio de la vieja aldea, porque el pueblo fue resignificado sin perder su condición de espacio comunitario.

A través de las historias de fundación y desarrollo de los treinta pueblos misioneros surgió el concepto de Región Cultural como desprendimiento de la antigua macro-región. Es decir, "el espacio resultó una construcción con estructura espacial sincrónica y diacrónica que incluyó al indio, al misionero y a la posterior etapa de formación nacional". (Levinton, 2009, p.264).

En los cambios y transformaciones de las reducciones hubo gran cantidad de rechazos y adaptaciones por parte de los jesuitas y de los indios. Sin embargo, siempre existió una firme voluntad de encuentro anclada en la fe y reforzada por los símbolos. Por eso, la aceptación de la ley cristiana en las poblaciones estuvo inseparablemente unida al edificio (iglesia/casa de Dios) y al misionero. El espacio simbólico del núcleo edilicio principal (iglesia/cementerio/huerta) tuvo su réplica en la plaza como sitio de encuentro entre lo humano y lo divino. Dentro de esta misma línea, en el complejo proceso de adaptación se lograron resignificar espacios, objetos y roles que guardaban un lugar relevante y hasta identitario en las comunidades indígenas: por ejemplo, la huerta, el corral, el baño, el agua y la distribución de las tareas. De hecho, el cambio de actividad de las mujeres que asumen las labores de la casa y los tejidos hace que los hombres (sin necesidad de salir a cazar) se dediquen al cuidado de los corrales y las huertas. De esta forma desaparece el culto animista relacionado con la caza y cobran un nuevo relieve los espacios internos de la 
misión y los espacios externos en cuanto proveedores de alimento.

Respecto de la huerta y del jardín, poseían la misma significación simbólica para padres como para indígenas. Representaban el sitio en donde el sujeto se aunaba con la naturaleza en una unión cosmológica con rasgos paradisíacos. La profusión de árboles, en especial, los frutales, acompañada por cursos de agua hacía que el hombre identificara esa realidad tangible con un espacio sacro.

Mucho se habla del poder de adaptación del indígena al modus vivendi misionero pero también es importante destacar la adaptabilidad de los padres jesuitas. Ejemplo de ello se observa en su capacidad de observación sobre la importancia que revestía el agua para los indígenas. Los religiosos respetaron el hábito del lavatorio diario, lo controlaron y lo acomodaron a sus pautas culturales de forma que las reducciones contaban con desagües sanitarios, reservorio de agua y un sistema de baños y fuentes.

La misión representó el sitio concreto en donde se produjo la unión de dos formas de ser muy diferentes: padres e indios se constituyeron en una síntesis cultural y religiosa. Los pueblos representaron un punto de encuentro entre el espacio terrenal y el celestial. De muros para adentro todo tenía un lugar adjudicado y cada espacio guardaba una relación simbólica que tendía a alcanzar un orden perenne, inmutable. Es por ello que nuestro estudio de la planta misional se ha centrado, por un lado, en el espacio inferior en donde se ubicaban las casas de los indios (sustento de la vida cristiana familiar), el cabildo y las casas de los caciques (unión del poder terrenal con la jerarquía) y, por el otro, el espacio superior con la iglesia (como su centro), el cementerio (representación de la vida trascendente y eterna) y la huerta (reproducción genesíaca de la Creación). Como centro aparece la plaza, prolongación de la iglesia, representando la unión del Cielo y la Tierra. Y, de manera general, todo el plano conformaba una figura de ocho lados que tradicionalmente constituye un símbolo de la muerte iniciática, del pasaje de un mundo a otro. Así, la reducción desde su planeamiento estaba concebida como el lugar en donde el indio renunciaba a su vida pagana y pasaba a vivir en una realidad sacra. Todos los espacios de la reducción fueron pensados como manifestaciones hierofánicas por las cuales el sujeto se encontraba inmerso en un lugar sagrado. Así, el afuera de la misión (mundo profano) contrastaba con el adentro (dimensión sacra). Y, finalmente, no podemos dejar de mencionar que frente a tamaña composición espacial y arquitectónica se suma también la dimensión lingüística, propia de la prédica de los padres, por la cual se produce la síntesis que suma lo manifestado (palabra) al signo que remite a lo inmanifestado. 


\section{Referencias Bibliográficas:}

\section{Fuente primaria}

RUIZ DE MONTOYA, Antonio. (1989). Conquista espiritual hecha por los religiosos de la Compañía de Jesús en las provincias de Paraguay, Paraná, Uruguay y Tape. [1639] Estudio preliminar y notas Dr. Ernesto Maeder. Rosario: Equipo Difusor de Estudios de Historia Iberoamericana.

\section{Fuentes secundarias}

ARANZUEQUE, Gabriel. (1997). Narratividad, fenomenología y hermenéutica. En Aranzueque, G. [ed.]. Horizontes del relato. Lectura y conversaciones con Paul Ricoeur. Madrid: Universidad Autónoma de Madrid.

AUGÉ, Marc. (1992). Non-lieux, introduction à une anthropologie de la surmodernité. Paris: Seuil BURKCHARDT, Titus. (1992). La civilización Hispano-árabe. Madrid: Alianza.

d’EVREUX, Yves. (1985). Voyages au nord du Brésil fait en 1613 et 1614. París: Ed. Hélène Clastres. --- (2012). Voyages au nord du Brésil (1615). Édition critique par Franz Obermeier, Kiel, Westensee Verlang, Die Deutsche Bibliothek, coll. "Fontes Americanae”, http://macau.unikiel.de/servlets/MCRFileNodeServlet/macau derivate 00000180/YvesDigitaleAusgabe.pdf?AC=Y [Consultado: 17-03-2015].

DESCOLA, Philippe. (2001). Construyendo naturalezas. En Naturaleza y Sociedad. Perspectivas antropológicas. México: Ed. Siglo XI.

DEL PERCIO, Daniel. (2011). Actas de las X Jornadas de Literatura Comparada. http://xjornadaslc.fahce.unlp.edu.ar/ [Consultado: 08-05-2015].

FOUCAULT, Michel. (1967). Des espaces autres (Conférence au Cercle d'études architecturales, 14 mars 1967) (En: Dits et écrits 1984. Tome IV, texte 360 http://foucault.info/documents/heteroTopia/foucault.heteroTopia.fr.html [Consultado: 20-04-2015] ---. (1987). Hermenéutica del sujeto. Madrid: Ed. De la Piqueta. 
HEIDEGGER, Martín. (1970). Carta sobre el Humanismo. Madrid: Paidós.

HUSSERL, Edmund. (1992). Invitación a la fenomenología. Madrid: Paidós.

GÂNDAVO, Pero de Magalhães. História da provincia Sancta Cruz a que vulgarmente chamamos Brasil. Feita por Pero Magalhães de Gândavo, dirigida ao muito Illustre senor Dom Lionis Pereira governador que foy e Malaca \& das mais partes do Sul da India. Impresso em Lisboa: na officina de Antonio Gonsalvez: vendese em casa de loão Lopez livreiro na rua nova, 1576. $-48 \mathrm{f}$. : il. ; $4^{\circ}$ (18 cm). Biblioteca Nacional de Portugal http://purl.pt/index/geral/PT/index.html [Consultado: 09-02-2015]

GONZÁLEZ TORRES, Dionisio. (1991). Cultura Guaraní. Asunción: RP edición.

MORO, CAMPANELLA, BACON. (1995). Utopías del Renacimiento. Estudio preliminar de Eugenio Ímaz. Méjico: Fondo de Cultura Económica.

RAMA, Ángel. (1998). La Ciudad Letrada. Montevideo: Arca.

RICOEUR, Paul. (1985). Hermenéutica y Acción. Buenos Aires: Ed. Docencia.

---. (1988). El discurso de la acción. Madrid: Cátedra.

---. (2007). Tiempo y narración: Configuración del tiempo en el relato histórico. México: Siglo XXI.

RUIZ, Irma. (2004). Las caída de los dioses y la dulcificación del mar: Secuelas de otra mirada sobre la arquitectura Mbyá-Guaraní. En: Revista de Indias 230 -2004.

VATTIMO, Gianni. (1992). Más allá del sujeto. Nietzsche, Heidegger y la hermenéutica. Barcelona: Paidós. 